\title{
Review
}

Mirostawa Pluta-Olearnik*

\section{International Brand Strategies. The Perspective of the Companies from Emerging Markets}

https://doi.org/10.2478/ijme-2020-0027

Warsaw School of Economics Press

The monograph by Marzanna Witek-Hajduk touches upon issues important for the contemporary development of knowledge about international brand strategies implemented by companies from the so-called emerging economies and markets (Latin America, Asia, Africa, China, and Eastern Europe). The author concentrates on the so-called "brand orientation of a company" and its significance for the strategy of creating a strong brand with an international outreach, especially in the context of shaping the international competitiveness of entities representing an emerging economy.

In general, International Brand Strategies. The Emerging Markets Perspective is an extensive study of a total of 355 pages, including an Introduction, five chapters, a Conclusion, and the corresponding tables. The layout of the publication is neat - the chapters have a clearly defined subject matter and an intelligible internal structure. Certainly, the rich bibliography is worth highlighting as in large part it contains publications by foreign authors and documents the author's excellent knowledge of the international achievements in the examined area.

With regard to the content of the individual parts of this extensive monograph, one needs to emphasize the logic and legibility of the argumentation noticeable in the internal layout of the publication. First, in the introduction to the book, the author formulates an ambitious set of research goals (theoretical, empirical, methodical, and practical), a list of research questions, and a group of research hypotheses concerning the realization of the empirical goal. There is also a diagram showing the subsequent stages of research carried out by the author, which is a good preparation for the further reading of this original work.

The first three chapters of Marzanna Witek-Hajduk's monograph are of a theoretical and cognitive nature and contain a full identification of the challenges for companies representing Eastern markets, in terms of creating international product brand strategies. The author directs the reader's attention to the new problem of brand management on the international market in the context of the resource management concept and the concept of a company's dynamic capabilities. It should be agreed that the main challenge for companies from the emerging markets is to adapt their internationalization strategies to their resources and competitive advantages, and to create or acquire key resources and capabilities, including brand management in foreign markets.

In Chapter 1, Brand and Enterprise Competitiveness, the author discusses, among other things, the potential of the brand as a source of competitive advantage in foreign markets, the elements of the brand orientation model and their relation to the performance of the brand and the organization, as well as the problem of international brand management in the context of the resource management concept and the dynamic capabilities concept of the enterprise.

Chapter 2, entitled International Expansion of Brands in the Light of Theoretical Concepts for the Internationalization of Companies, is entirely based on a detailed review of the literature on foreign business, trade, and international marketing and facilitates identifying possible strategies for the expansion of brands into foreign markets. There appears an important thread suggesting that the

*Corresponding author: Mirostawa Pluta-Olearnik, Faculty of Business and Management, Wroclaw University of Economics and Business, Wroclaw, Poland. E-mail: Miroslawa.Pluta-Olearnik@ue.wroc.pl 
internationalization of specific brands of manufacturers or products and their portfolios is often a consequence of an increase in the company's involvement in foreign markets, and a consequence of the adopted competitive strategy, for example, in the case of small- and medium-sized enterprises.

Chapter 3 of the book, International Brand Strategies: Essence, Content, and Context, contains, among other things, a useful discussion of many, often ambiguous, terms encountered in brand research to date. The author also points out some specific internal and external conditions of the international brand strategy and discusses the contemporary understanding of the country of origin effect in the context of brand strength and awareness.

Chapter 4, International Brand Strategies of Enterprises from the Emerging Markets, is one of the most important in the monograph. The author identifies here the rationale for internationalization and the specifics of the strategy of competing companies from the emerging markets and economies from various regions of the world, that is Latin America, Asia, Africa, China, and Eastern Europe. In addition, she addresses the poor image of the country of origin of the product which companies from the emerging markets struggle with. She also analyzes options for international brand portfolio strategies and positioning their image.

Chapter 5, the final chapter of the monograph, entitled International Brand Strategies of Polish Companies - The Concept and Results of Empirical Research, contains a description of the procedure and results of the quantitative research carried out within a group of 142 Polish companies (managers of exported brands and consumer goods). The results of this research enabled the author to verify her conceptual model, which shows the impact of the indicated determinants (internal and external) on the international brand strategy, and then the impact of this strategy on the results of the leading brand on the foreign market and the results of the company (with the moderating variable of the company size). Next, the author presents the structural model of the examined relations and evaluates the quality of the measuring model and structural model in order to obtain confirmation, or lack thereof, for the accepted research hypotheses.

To sum up, thanks to extensive and in-depth research into the world's achievements to date and methodically advanced procedure of empirical research, the author has fully achieved the ambitious goals of the monograph. I am convinced that the conceptualization of knowledge and the multidimensional analyses and their results reliably document the nature of brand influence on the international competitiveness of the enterprises from the emerging markets, including Polish enterprises. The author has successfully identified and filled the existing gaps in the existing knowledge of business management and its particular resource - the brand on foreign markets - in conditions of growing competitiveness. Moreover, she has indicated specific practical recommendations for Polish enterprises in the area of internationalization of brand strategy and the so-called limitations of research and directions of further research.

Bearing in mind the numerous commendable qualities of Marzanna Witek-Hajduk's monograph, International Brand Strategies. The Perspective of the Companies from the Emerging Markets, I can confidently recommend it to potential customers, especially to representatives of the scientific and business community and students, interested in building strong product brands on international markets and in creating their positive image. The publication provides comprehensive, up-to-date, and modern knowledge in this area. 